\title{
FEATURES REGARDING INTERACTION OF ANCHOR PILES SUCH AS “TITAN" AND "GEOIZOL" WITH SOILS
}

\author{
Mikhail. I. Nikitenko ${ }^{a, *}$, Igor P. DubatovkA ${ }^{b}$ \\ a Stroitechnorm, Stroikompleks, 220037, Minsk, ul. Filimonov, 8-105. Belarus \\ ${ }^{b}$ Monorakurs, 220116, Minsk, pr. Dzerzhynsky, 104b. Belarus \\ * corresponding author: michnikit@gmail.com
}

ABstract. The article describes the experience of using anchors at a deep excavation for the construction of a multifunctional complex in Minsk. The authors describe the features of the device and the testing of the pressure grouted anchoring structure of "Geoizol" (according to the "Titan" type system).

KEYWORDS: deep excavation pit; underground retaining wall; anchor piles Titan, Geoizol..

\section{INTRODUCTION}

Cut-off diaphragm wall was used for the protection of the deep excavation in the construction of a multifunctional complex in Minsk. These walls were anchored with anchors at one, two or three levels. [1]

"Geoizol" anchors according to "Titan" type were used for anchoring of the diaphragm walls. These piles were installed with the help of pressure grouted technology [2 8]. As these anchor piles differ from conventional continuous pressure grouted anchors the nature of these differences will be described. At the end the advantages and disadvantages of the described anchor piles during their installation and application are specified.

\section{Construction site}

Multifunctional complex (IFC) is situated in the northeast of Minsk. The geotechnical site conditions were described as rather complicated, composed from different horizons, as Holocene, Mogilev, Slavgorodskiy, Dniprovskiy, which contains mostly moraine sediments of different compositions. Starting from boulders up to fine sandy loam, arranged not only in layers, but sometimes in the shape of closed lenses. Top aquitard are moraine loam Mogilev sub horizon, lower - moraines Slavgorod sub horizon. Between them is artesian water, non-aggressive to concrete. The amount of pressure was $9.0-13.6 \mathrm{~m}$.

\section{Constructive solution of ANCHOR "TITAN" PILES AND "GEOIZOL"}

The design of the anchor rod comprises a steel tubular rod with a helical knurled outer surface consisting of joined screw couplings units, and on the bottom of which at the end there is screwed a drill bit with outlet holes, and at the top there is a lock nut with a spherical contact surface which rests on the construction plate (Fig. 1). In this design concept the hollow anchor rod

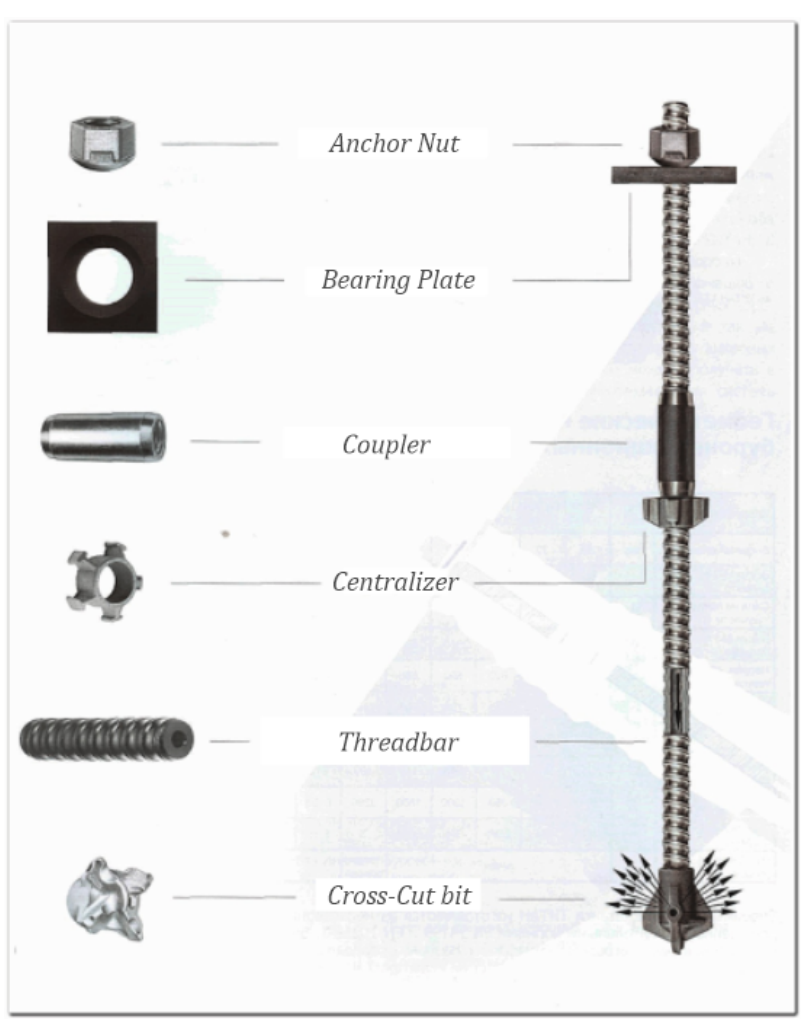

FiguRE 1. Structural elements of anchor piles "Titan" and "Geoizol"

combines the functions of a drilling rod when drilling wells through a progressive rotational movement of the rod with a drill bit, and an injector for injecting into the cavity a cement slurry, which, under pressure erodes at the bottom soil and under agitation then plugging the borehole, creating a hardening of shaft piles. Subsequently the rod reinforces the pile and on pulling out it provides a recognizable tensile force. 


\section{Sequence of operations When CONSTRUCTING THE TYPE OF

ANCHOR PILES "TITAN" AND
"GEOIZOL"

The technological operations of the device anchor piles in the soil include borehole drilling to the projected depth of the tubular rod in rotation together managed with drilling crown and soil displacement. This is pumped through the rod chamber plugging cement slurry which erodes soil and facilitates drilling of the downhole, fills it and prevents soil collapse. When the cement slurry strength attains at least $70 \%$ of that designated (in sand - 14 days during solution without plasticizer C-2 and 7 days - with plasticizer), all are subject to tension anchor piles. In clayey soils a drainage solution is needed.
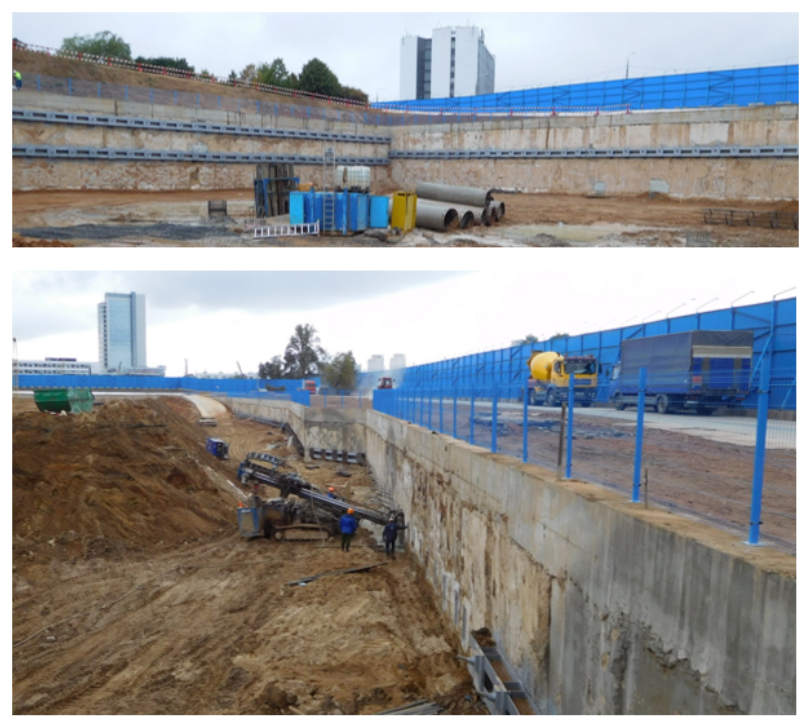

FiguRE 2. Excavation pit overview and installation of anchoring piles.

After the excavation of the construction site on the level of the first row of anchors, horizontal I beam was applied together with large steel plates, Fig. 2 After that the anchoring piles were constructed. The lengths of anchor piles with diameter $0.25 \mathrm{~m}$, was at first level $15 \mathrm{~m}$ and $12 \mathrm{~m}$ for the second level. The lengths of the workers (root) segments were $8.4 \mathrm{~m}$ and $6.9 \mathrm{~m}$. They were located in the strata of sandy loam.

\section{Anchoring Piles testing}

Anchors testing should evaluate the shear strength of sandy loam along the trunks and roots of the anchoring piles and help a confirmation of shear strength used during the stability of retaining wall design.

First three anchors are designed to identify the role of the injected grout composition to set them quality strength after 7 days, and also for definition of the actual barrel shape and diameter. To prove this the anchors were excavated (see Fig. 3). The excavation was carried out by inspection and measurements. The control showed that their trunks are roughly cylindrical in shape with a diameter of $0.25 \mathrm{~m}$ without separation of free and working root segments. It was established that the strength of cement grout in all samples was similar, reaching over $70 \%$ of the calculated value. The arrangement for the pull-out tests is shown on Fig. 4. Maximum tensile force was $549 \mathrm{kN}$, indicating the average shear strength along perimeter and length of anchoring part equal to $140 \mathrm{kPa}$.

Two other testing anchors were left in ground for 28 days. For one of them the hardening accelerator was used and the second anchor was constructed without hardening accelerator. No significant differences were observed.

\section{Advantages And disadvantages OF THE ANCHOR OF THE "TITAN" PILES OR "GEOIZOL"}

Testing of 5 anchoring piles and their excavation allows some statement about the application of these anchors. Advantages are as follows:

- Structural design ensures that the high strength hollow rod with knurling screw on the outer surface and with cross-cut bit at the bottom allows insertion of the anchor into ground, followed by injection of grouting cement slurry under high pressure. Slurry primarily wash away soil at the bottom, supports borehole stability and after hardening guarantee good contact with rod surface;

- Minimal elongation of high strength anchor rod during loading;

- Low risk of corrosion. However there are also some shortcoming as:

$\triangleright$ The creation of a local broadening on the lower end of the pile, i.e., working in the root zone is problematic, since the liquid cement slurry further pumping of denser high-pressure pressure leads approximately to the same stem diameter across the length of the borehole, with the exception of more intensive compressible soil layers;

$\triangleright$ The huge over expenditure of cement due outpouring of wellhead in the process of drilling or during injection;

$\triangleright$ Hardening cement slurry is excluded because it is difficult to rotate the rod with the drill bit, while increasing their water-cement ratio $(\mathrm{w} / \mathrm{c})$ sedimentation processes are amplified.

Up to now experiences in low permeable ground leads to the recommendation to use drainage to drain excess of water from the slurry injected with a great value of $\mathrm{w} / \mathrm{c}$ in accordance with the inventions as are No 1281635, 1527378 and 1392203 see [3, [6]. Application of geotextile sleeve can fulfil this drainage role. 
a)

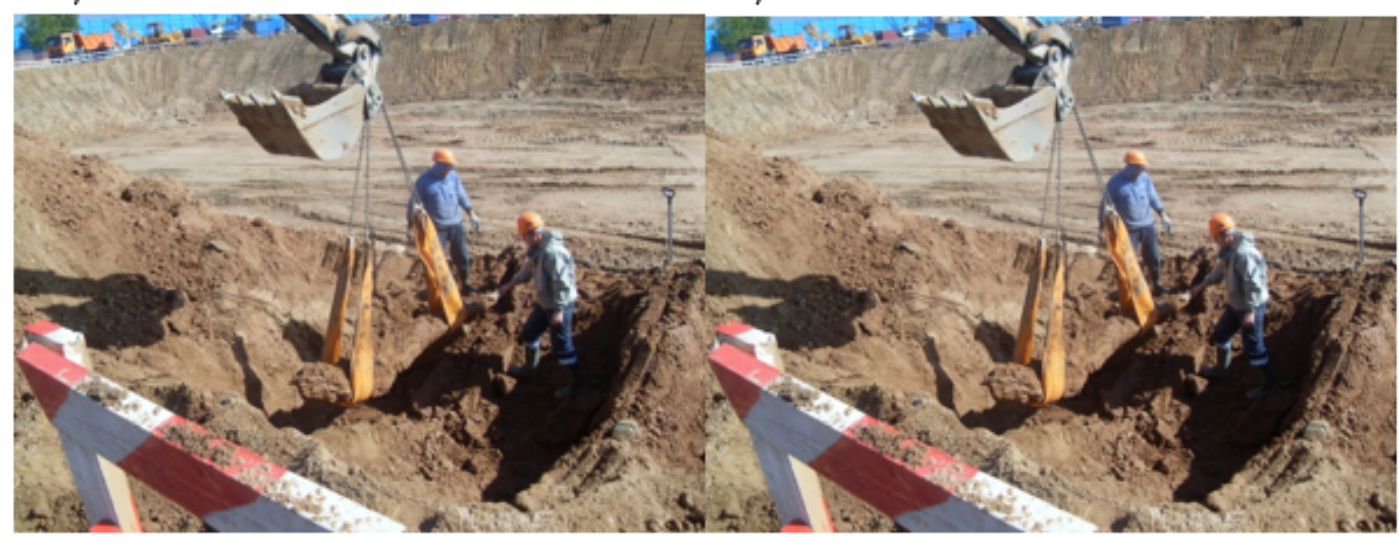

c)

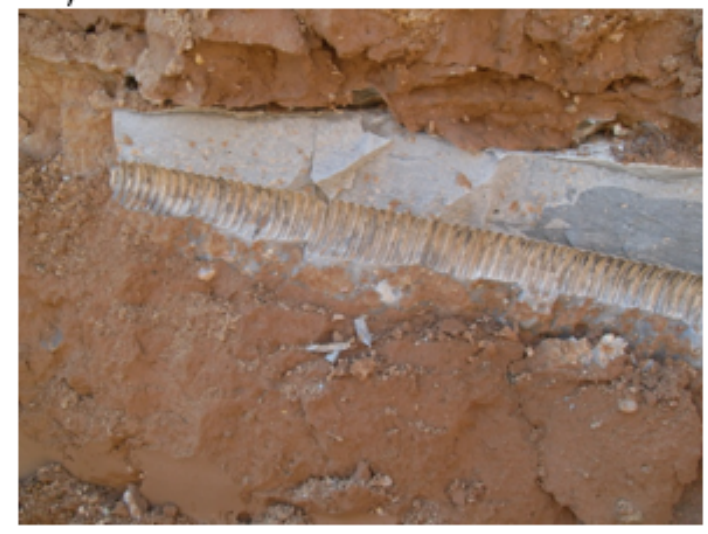

b)

d)

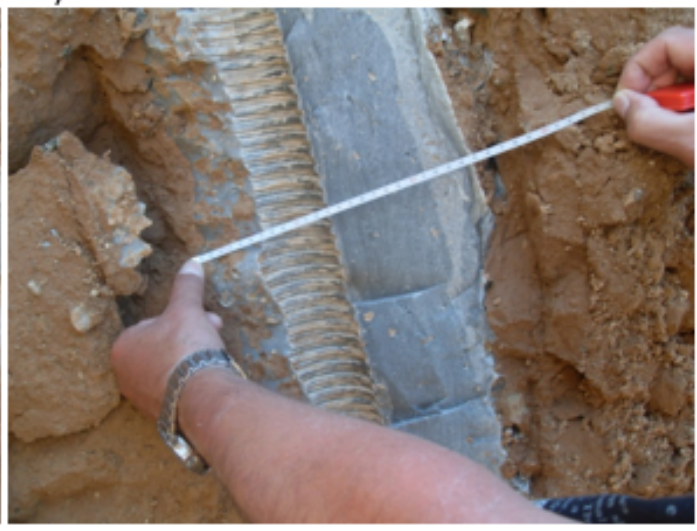

FiguRE 3. Removing from the ground (a) The form of excavated three anchor piles (b). Fragment of anchor piles body remaining in the ground (c), Measurement of the diameter on the contact with the stem (d).
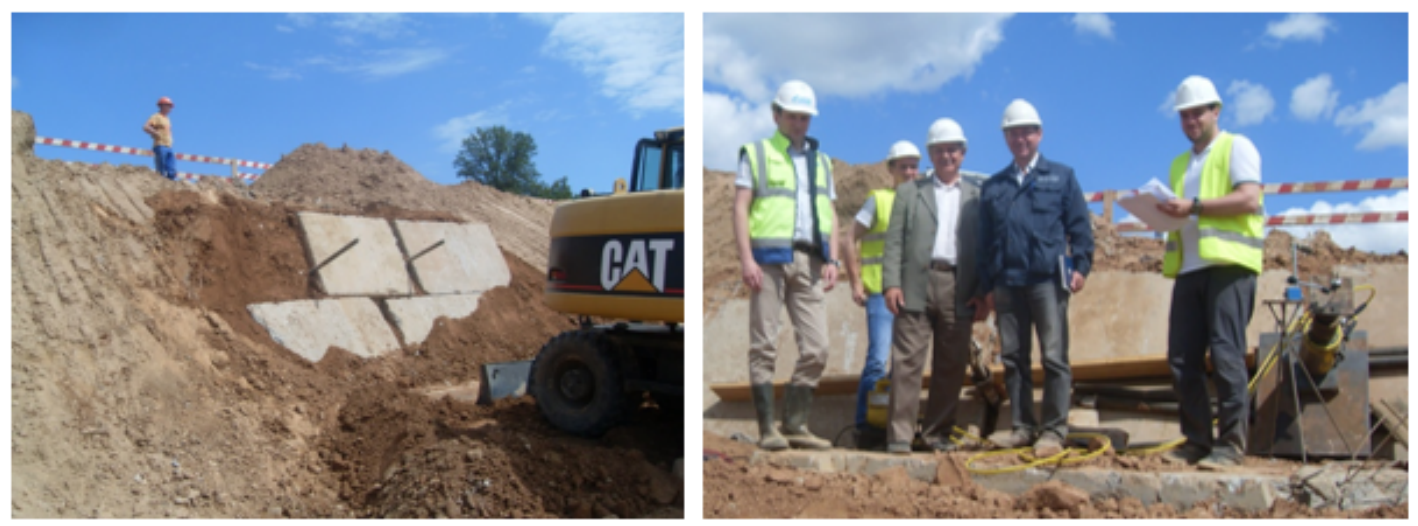

FigURE 4. Assembling panels of support system for two experienced anchor piles and sampling testing for one of them.

\section{Conclusions}

Testing of the anchoring piles of the type "Titan" and "Geoizol" on the construction site in Minsk, make it possible to specify not only advantages of this system, but also some shortcomings. To partly eliminate the shortcomings some recommendations were proposed namely draining geotextile sleeve with local tire rings along the length of the roots and packers.

\section{REFERENCES}

[1] P. Posobie. Designing and organizing the pile and wall in trench. 14-01 for SNB 5.01.01-99. Architecture and Construction Ministry of Belarus, Minsk, 2002.

[2] P. Posobie. Design and construction of bored piles. 13-01 for SNB 5.01.01-99. Architecture and Construction Ministry of Belarus, Minsk, 2002.

[3] P. Posobie. Designing and construction of injection anchor and piles. 18-04 for SNB 5.01.01-99. Architecture and Construction Ministry of Belarus, Minsk, 2005. 
[4] TKP. Foundations and underground structures, constructed with the use of inkjet technology. Terms of design and construction. 45-5.01-45-2006 (02250). Architecture and Construction Ministry of Belarus, Minsk, 2006.

[5] M. I. Nikitenko. Continuous pressure grouted piles and anchors in the construction and reconstruction of buildings and structures. Belarusian National Technical University, Minsk, 2007.
[6] A. G. Malinin. Application of anchor "Atlant" piles in underground construction. Earth Science 2:248-254.

[7] C. A. Ritov. Effective modern device technology of continuous pressure grouted piles and injecting anchors. Information Bulletin 16(1):7-14.

[8] C. Zolotov. About the bases of the device anchor piles titan. Construction and Real Estate pp. 1-3. 